\title{
Functional Neuromuscular Stimulation in 4 Patients with Complete Paraplegia
}

\author{
N. Hjeltnes, MD, ${ }^{1}$ A. Lannem ${ }^{2}$ \\ ${ }^{1}$ Specialist in Physical Medicine and Rehabilitation, ${ }^{2}$ Physiotherapist, Sunnaas \\ Hospital, 1450 Nesoddtangen, Norway.
}

\section{Summary}

The effect of functional neuromuscular stimulation (FNS) on muscle strength and endurance was studied in 3 patients with long-standing complete injuries (T7-T12) and in 1 patient with a recent complete injury (T5). All 4 patients became strong enough to rise, stand and to walk a few steps within parallel bars. However, only 1 patient was able to walk without parallel bars $(60 \mathrm{~m})$. The energy demand of FNS-assisted walking was measured to be more than $60 \%$ of the maximal endurance capacity of this patient. This finding partly explains the low patient acceptance of FNS.

Key words: Paraplegia; Functional neuromuscular stimulation; Isokinetics; Oxygen uptake.

Functional electrical stimulation (FES) is the use of electricity to overcome a neurological deficit (Ray, 1978). When the target organ is skeletal muscles, the method is called functional neuromuscular stimulation (FNS) (Peckham, 1981). FNS has been found to increase the capillary density in muscles (Brown et al., 1976) and to increase the skin blood flow (Hellsing, 1986). It also improves the fatigue resistance by increasing the oxidative metabolism in the stimulated muscles (Riley et al., 1973). However, the superior object of FNS is to improve the functional abilities of patients by increasing the strength of paralysed or paretic muscles in those with an upper motor neuron lesion (Cybulski et al., 1984; Liberson et al., 1961; Stefanovska and Vodovnik, 1985).

So far, only limited experience with FNS on small populations of subjects have been obtained in any single centre in the world, and although results today demonstrate impressive function, clinical acceptance is low and user rejection rate is high due to lack of ease, reliability and efficiency (Brindley, 1978-1979; Peckham, 1987).

In spite of limited technical resources, we decided to carry out our own FNS project in Sunnaas Hospital in 4 subjects with complete paraplegia. The main aim of the study was to strengthen the quadriceps muscles sufficiently to make the subjects rise, stand and walk for short distances. In addition we wished to acquire 
and broaden our experience with the effect of FNS on the strength and fatigue in centrally denervated muscles. We also wanted to learn more about the positive and negative side-effects of FNS.

\section{Patients}

Four patients with complete paraplegia were chosen for the study after they gave their informed consent (Table I). They were all classified as Frankel A with injury levels between $\mathrm{T} 5$ and T12. Their upper motor neuron type of lesions were verified also by nerve conduction velocity- and H-reflex latency measurements (Table II). Three of the patients $(1,2,3)$ had long-standing injuries, while the fourth was injured only 3 months before the study started. Patient 3 had used FNS for a period of 1 year previously.

Table I Subjects in the study

\begin{tabular}{|c|c|c|c|c|c|c|c|c|c|c|}
\hline $\begin{array}{l}\text { Subject } \\
\text { no. }\end{array}$ & Sex & $\begin{array}{l}\text { Age } \\
\text { Years }\end{array}$ & $\begin{array}{l}\text { Height } \\
(\mathrm{cm})\end{array}$ & $\begin{array}{l}\text { Weight } \\
(\mathrm{kg})\end{array}$ & $\begin{array}{l}\text { Years } \\
\text { from } \\
\text { injury }\end{array}$ & $\begin{array}{l}\text { Level of } \\
\text { injury }\end{array}$ & Spastisity & Function & $\begin{array}{l}\text { Use of } \\
\text { KAFO }\end{array}$ & $\begin{array}{l}\text { Previous } \\
\text { Complications }\end{array}$ \\
\hline 1 & $\mathrm{~F}$ & 23 & 160 & 50 & 5 & Th12 & Slight & $\begin{array}{l}\text { Wheelchair } \\
\text { user } \\
\text { Independent }\end{array}$ & $\begin{array}{l}\text { For } \\
\text { training }\end{array}$ & None \\
\hline 2 & $\mathrm{~F}$ & 25 & 179 & 63 & 5 & Th7 & Moderate & $\begin{array}{l}\text { Wheelchair } \\
\text { user } \\
\text { Independent }\end{array}$ & $\begin{array}{l}\text { For } \\
\text { training }\end{array}$ & None \\
\hline 3 & $\mathrm{~F}$ & 20 & 170 & 61 & 5 & Th7 & Moderate & $\begin{array}{l}\text { Wheelchair } \\
\text { user }\end{array}$ & No & $\begin{array}{l}\text { Pressure sore } \\
\text { (Plastic surgery) }\end{array}$ \\
\hline 4 & $M$ & 36 & 177 & 70 & $1 / 4$ & Th5 & Severe & $\begin{array}{l}\text { Independent } \\
\text { Wheelchair } \\
\text { user } \\
\text { Independent }\end{array}$ & $\begin{array}{l}\text { For } \\
\text { training }\end{array}$ & $\begin{array}{l}\text { lleumbladder } \\
\text { None }\end{array}$ \\
\hline
\end{tabular}

$\star \mathrm{KAFO}=$ Knee Ankle Foot Ortotic

Table II Nerve conduction velocities and H-reflex studies below injury level

\begin{tabular}{lcccc}
\hline & NCV & \multicolumn{2}{c}{ H-reflex } \\
Subject & N. per. & N. fem. & Latency & H/M-ratio \\
No. & $($ M/sek $)$ & $($ M/sek $)$ & $($ M/sek $)$ & \\
\hline 1 & $41 \cdot 3$ & $64 \cdot 2$ & $27 \cdot 8$ & $0 \cdot 43$ \\
2 & $46 \cdot 1$ & $61 \cdot 2$ & $31 \cdot 0$ & $0 \cdot 54$ \\
3 & $43 \cdot 3$ & $61 \cdot 0$ & $33 \cdot 2$ & $0 \cdot 35$ \\
4 & $44 \cdot 2$ & $60 \cdot 0$ & $32 \cdot 8$ & $0 \cdot 89$ \\
\hline
\end{tabular}

\section{Stimulators}

Three different types of electrical stimulators were used (Table III). Only the Microstim was satisfactorily described and specified by the distributor (Medistim $\mathrm{A} / \mathrm{S}$ ). The other two (from Socca and Enablement Technology) were without 
Table III FNS stimulators and selected stimulation parameters

\begin{tabular}{lccc}
\hline Characteristics & Microstim & $\begin{array}{l}\text { Stimulators } \\
\text { Socca }\end{array}$ & 'Port talbot' \\
\hline $\begin{array}{l}\text { Current wave } \\
\text { form }\end{array}$ & $\begin{array}{l}\text { Rectangular } \\
\text { biphasic } \\
\text { Constant } \\
\text { current }\end{array}$ & $\begin{array}{l}\text { Monophasic } \\
\text { Constant } \\
\text { voltage }\end{array}$ & $\begin{array}{l}\text { Biphasic } \\
\text { Constant } \\
\text { voltage }\end{array}$ \\
$\begin{array}{l}\text { Frequency }(\mathrm{HZ}) \\
\begin{array}{l}\text { Impulse width } \\
\text { (msec) }\end{array}\end{array}$ & 0.3 & 20 & 20 \\
$\begin{array}{l}\text { Stim. amplitude } \\
\text { (upper limit) }\end{array}$ & $99 \mathrm{MA}$ & $250 \mathrm{~V}$ & 0.3 \\
$\begin{array}{l}\text { Electrodes } \\
\text { Number of }\end{array}$ & $\begin{array}{c}\text { Polartrode } \\
\text { (TM) }\end{array}$ & $\begin{array}{c}\text { Polartrode } \\
(\mathrm{TM})\end{array}$ & $\begin{array}{c}\text { Rubber } \\
+ \text { gel. }\end{array}$ \\
channels & 2 & 4 & 4 \\
\hline
\end{tabular}

written instructions, and were therefore technically controlled by SI (Norwegian Institute of Industrial Research). The maximal stimulation amplitude in all three stimulators exceeded the upper current limit allowed by the National Electrical Control Organisation (NEMKO). In the Microstim, stimulation could be given sequentially or at the same time in both channels. The 4-channel Socca stimulator was preprogrammed for biped walking. Polartrode TM superficial electrodes (rectangular $3.5 \times 8.5 \mathrm{~cm}$ and circular $3 \mathrm{~cm}$ diameter) were chosen for the stimulation of the quadriceps muscles and of the common peroneal nerve, respectively.

\section{Orthopeadic and technical aids}

Polypropylene ankle-foot orthoses were used to stabilise the ankle joint during training. A flexible walking frame (mod. Carter) was used for support in the standing position, as well as during biped walking. Switches and current conductors connected to the Socca stimulator were placed in the handles of a pair of crutches for the purpose of walking.

\section{Methods and procedure}

All patients were examined neurologically. Motor nerve conduction velocity was measured in the femoral nerve bilaterally as were also the $\mathrm{H}$-reflex latencies (Table II) by means of the Dantec System 2000 M. During the testing and training periods, each quadriceps muscle was stimulated by means of 2 pairs of electrodes, meaning 2 channels or 1 stimulator for each muscle. Before we decided where to place the stimulating electrodes, we studied the knee extension torque related to different electrode placements during constant stimulation amplitude. Direct stimulation of the femoral nerve doubled the knee extension torque compared to any other placement of the electrodes. However, since the distance between the nerve and the skin electrodes changed during the movements, this stimulation site 
could not be used. So the electrodes were placed on those motor points of the quadriceps muscle itself, giving the highest peak torque.

Knee extension torque due to the electrical stimulation was measured by means of the Cybex isokinetic dynamometer (Lumex Inc.; Hjeltnes and Pedersen, 1983; Thistle et al., 1967). Peak torque and the area (work) below the torque/angular displacement curve were registrated at angular velocities from $\mathrm{O}^{\circ}$ second (isometrically) to $240 \%$ second (Hjeltnes and Pedersen, 1983). Muscular fatigue during FNS was measured as time to $50 \%$ of initial peak torque at angular velocities of 30 and $90 \%$ second. All measurements were carried out at monthly intervals. The thigh circumference was also measured monthly $20 \mathrm{~cm}$ above the lateral femur condyle.

Only the Socca stimulator was used for biped walking. Two channels stimulated each leg-one for the muscle quadriceps (knee extension) and one for the common peroneal nerve (flexion reflex)-so that the right knee was extended when left flexion reflex was stimulated, and vice versa. The patient controlled the cadence by means of the stimulator's on/off switches in his hands. Walking distance was measured by a tape measure, and the time was registered by a stopwatch.

A blood specimen was taken weekly for the analysis of CK. The physical endurance capacity (peak $\mathrm{VO}_{2}$ ) was measured 3 times during the study by means of the Gold system 9000 IV (Hjeltnes, 1986). The same equipment was also used to measure energy demands of FNS training (sitting, rising, standing, walking).

The heart rate was measured continuously during the training periods by means of the Sport-test system (Finland). Video (Panasonic VHS) tape recording was used to give visual feedback to the patients during training as well as to evaluate the progress in performance.

The patients kept a concise diary during the whole project.

\section{FNS training}

During the initial 4 weeks of the project the quadriceps muscle was strengthened by isokinetic resistance $(90 \%$ second). The FNS stimulator's on period lasted 1.5 seconds and the off period lasted 8.5 seconds. The knee extension torque was continuously recorded, and each exercise period ended when the torque approximated $50 \%$ of its initial value. The patients began with 2 training sessions daily, each of 5 to 10 minutes duration. After 4 weeks they could sustain 4 or 5 periods lasting more than 30 minutes. At that time the instrumental stimulation on period was increased to 4 seconds and the off period was reduced to 6 seconds. The patients still trained isokinetically, but, the angular velocity was reduced to $30 \%$ second, and bouts of isotonic knee extension (sitting on a quadriceps-bench) were added.

After 8 weeks of FNS exercise, the stimulator's on time was reduced to 3 seconds, and its off time to 3.5 seconds. The knee extension torque now approximated the critical lower level for standing (Brindley et al., 1978-1979; Cybulski et al., 1984; Isakov et al., 1985; Stefanovska and Vodovnik, 1985). Consequently rising and standing was integrated in the training programme for all patients, 2 periods each day, each lasting until fatigue occurred (flexion of the knees). Initially the patients stood on bathroom scales in parallel bars to control the weight-bearing on their legs.

From now on only subjects 1 and 4 were still trained in hospital, while subjects 
2 and 3 trained at home and only visited the hospital once a week for strength measurements. The quality as well as the quantity of the FNS training was therefore individualised. Only subject 1 went through all the planned stages of FNS ambulation training (Parallel bars, walking frame, crutches).

\section{Results}

\section{Subject 1}

In this subject the knee extension torque was more than doubled in less than 10 weeks to reach approximately $30 \mathrm{Nm}$. The isokinetic torque followed closely the

SUBJ. 1

SUBJ. 2

SUBJ. 3

SUBJ. 4

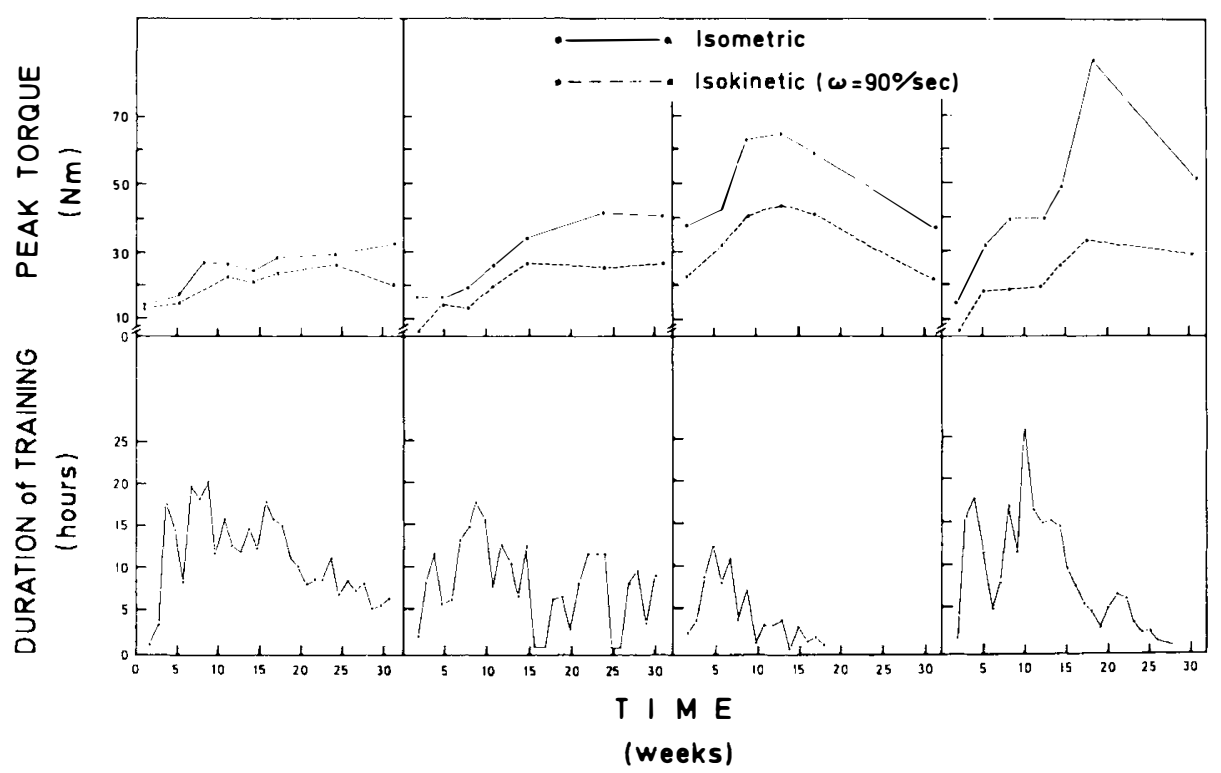

Figure 1 Changes in peak isometric and isokinetic ( $90 \%$ second) knee extension torque (following FNS) during the project period in each of the 4 patients (upper panels), compared to the weekly amount of training (lower panels).

isometric (Fig. 1). The muscular endurance improved even more, reaching 5 times the initial value within 3 weeks of FNS training (Fig. 2). Thigh circumference increased from 41.5 to $45 \mathrm{~cm}$ within 10 weeks and stabilised at that length. CK values were found slightly elevated at a few occasions $(\approx 300 \mathrm{u} / \mathrm{l})$. The physical endurance capacity of this subject started relatively high (peak $\dot{\mathrm{VO}}_{2} 28$ $\mathrm{ml} / \mathrm{kg} / \mathrm{minute}$ ) and became even higher ( $31 \mathrm{ml} / \mathrm{kg} /$ minute) during the project. This subject managed FNS biped ambulation in parallel bars within 3 months. After 6 months she managed biped FNS assisted walking for 30 minutes without rest in parallel bars, and she also walked continuously more than $60 \mathrm{~m}$ only supported with FNS and walking frame or crutches. During the whole training period, short lasting periods with superficial skin irritation close to the stimulating electrodes were observed. Improved bladder capacity, less frequent voiding and absence of 


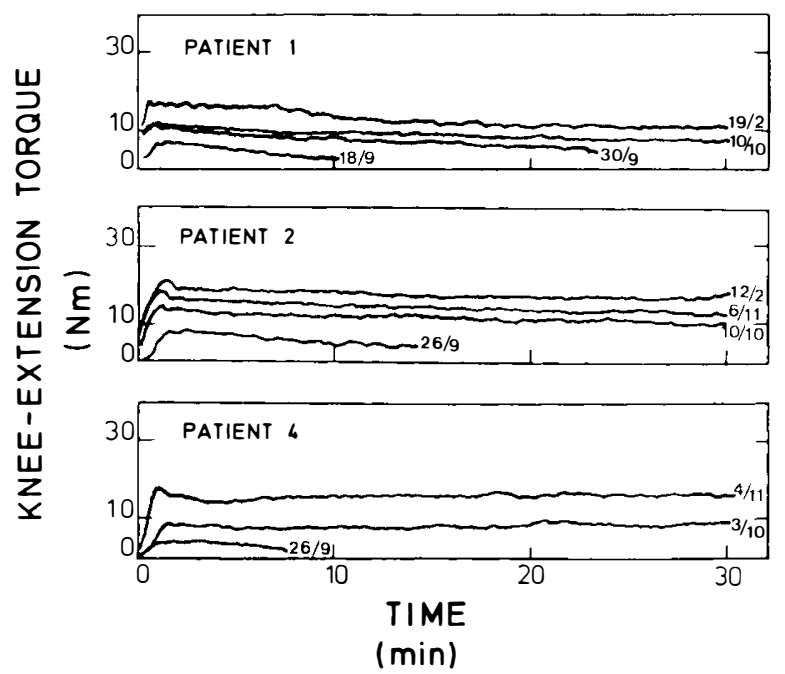

Figure 2 The muscular endurance of $m$. quadriceps during FNS in 3 of the patients, at 3 (patient 4) or 4 (patients 1 and 2) points of time during the project.

urinary tract infections were reported during the project. This subject clearly demonstrated the heavy demands that were put upon the circulatory system during

Table IV: Cardiorespiratory strain during ambulation with crutches and FES or crutches and KAFO* in 1 subject with complete TH12 paraplegia

\begin{tabular}{|c|c|c|c|c|c|c|c|c|}
\hline $\begin{array}{l}\text { Gait } \\
\text { assistance }\end{array}$ & & $\begin{array}{r}\text { Dist. } \\
M\end{array}$ & Strides & $\begin{array}{l}\text { Time } \\
\text { min sec. }\end{array}$ & $\begin{array}{l}\text { Peak FH } \\
\text { PR. min }\end{array}$ & $\begin{array}{l}\dot{\mathrm{VE}} \\
\mathrm{L} / \mathrm{min}\end{array}$ & $\begin{array}{l}\dot{\mathrm{V}} \mathrm{O}_{2} \\
\mathrm{ML} / \mathrm{kg} / \mathrm{min}\end{array}$ & $\mathbf{R}$ \\
\hline FES & test 1 & 30 & 136 & $5 \quad 59$ & 155 & 30 & 17 & 0.92 \\
\hline ('4 PT’) & test 2 & 30 & 111 & 359 & 170 & 30 & 18 & $0 \cdot 85$ \\
\hline KAFO & test 1 & 30 & 144 & $5 \quad 15$ & 144 & 23 & 12 & 0.92 \\
\hline (‘4 PT’) & test 2 & 30 & 149 & $6 \quad 29$ & 149 & 22 & 15 & 0.78 \\
\hline KAFO & test 1 & 30 & 50 & 200 & 160 & 37 & 20 & 0.95 \\
\hline \multicolumn{9}{|c|}{ ('swing-through') } \\
\hline
\end{tabular}



the different types of ambulation (Table IV) taxing between $50 \%$ and $70 \%$ of the aerobic capacity of the subject and between $75 \%$ and $90 \%$ of the heart rate reserve (Hjeltnes and Vokac, 1979). Biped walking with FNS and crutches became faster than biped walking with KAFOS and crutches, but reached only half the speed of the swing-through gait.

\section{Subject 2}

The isometric and isokinetic peak torque in this subject as well as the muscular endurance, showed the same amount of increase as in subject 1 (Fig. 1, Fig. 2). The thigh circumference increased by $3 \mathrm{~cm}$ on the right side and $1.5 \mathrm{~cm}$ on the left side. CK values kept stable and normal. The physical endurance capacity 
(peak $\mathrm{VO}_{2}$ ) was increased by $30 \%$ within 20 weeks. This subject never walked by means of FNS outside parallel bars. However, she continued to train knee extension, raising and standing very regularly by means of FNS and a specialised standing chair (Medema).

During the study, this subject experienced reduced ankle oedema, and warmer legs.

\section{Subject 3}

This subject had bought her own FNS equipment (from Enablement Technology) 2 years before our project started. Due to circumstances and lack of motivation, she had done very little training in the previous 6 months. She was initially much stronger than subjects 1 and 2, but the difference between isometric and isokinetic extension torque was greater (Fig. 2). Her muscular endurance was good from the beginning. Within 3 months she could take a few steps with FNS and her walking frame. However, she got a new job and became very occupied. The training became irregular and at times it was partially neglected (Fig. 2). Consequently function deteriorated and thigh circumference decreased. She suffered one ankle distortion during standing.

\section{Subject 4}

In this subject FNS started only 3 months after injury. Therefore FNS became part of the primary rehabilitation programme. Initially after a few FNS exercise periods, the knee extension torque was almost zero. However, within a few weeks he regained strength and gradually became very strong (Fig. 2). Four months after beginning of the project, his isometric extension torque approximated $50 \%$ of what is expected in healthy persons (Hjeltnes and Pedersen, 1983). The isokinetic torque at $90 \%$ second on the contrary never exceeded $35 \mathrm{Nm}$, due to the development of very heavy muscle spasms. Even though this patient trained regularly (up to 25 hours per week) and ultimately managed to walk by FNS in parallel bars, the spasms increased in proportion to his muscle strength in spite of a high dose of antispastic medication. Ultimately there was no choice but to stop exercising with FNS. The physical endurance capacity of this patient kept constant at a relatively low level $(20 \mathrm{ml} / \mathrm{kg} /$ minute $)$. Thigh circumference kept constant during the whole project and $\mathrm{CK}$ values at two occasions reached significantly elevated values $(>1200 \mathrm{U} / \mathrm{L})$.

\section{Discussion}

The results of this study show that FNS is an efficient training method to increase the strength and the endurance of paretic muscles in patients with upper motor neuron lesions, irrespective of the injuries being short- (subject 4) or long-standing (subjects 1, 2, 3). We used the same stimulation frequency $(25 \mathrm{~Hz})$ and the same pulse width $(0.3 \mathrm{msec})$ as recommended by others (Stefanovksa and Vodovnik, 1985). However, much of the training in this project was done isokinetically, and the stimulator's on and off periods were changed according to the changes of the angular velocity of the Cybex' equipment. From a theoretical point of view, 25 
$\mathrm{Hz}$ might recruit both slow twitch and fast twitch fibres and isokinetic training should give better results than isometric and isotonic training (Grimby, 1982). The muscular endurance, however, obviously increased more than the peak torque, probably because $25 \mathrm{~Hz}$ gave a more physiological stimulus for the slow twitch fibres than for the fast twitch fibres (Lømmo, personal communication). In agreement with earlier reports, we did not exercise the flexion reflex more than during the ambulation training (Cybulski et al., 1984; Isakov et al., 1985). The best functional results were reached in the 2 subjects with the lowest quadriceps strength, indicating that other factors such as injury level, physical endurance capacity, motivation, and medical complications play a decisive role. Thus subject 1 was the smallest, with the lowest body weight and with the best trunk stability.

The energy demand during FNS assisted ambulation (Table IV) partly explains why even patient 1 found it difficult to continue this form of ambulation over short distances at home. However, the results of this study indicate that in patients with complete injuries, the T12 level with an intact spinal cord below injury, was the most suitable for FNS.

The significant increase of the thigh circumference was probably due to muscle hypertrophy. This hypertrophy was strictly localised to that part of the muscle which was stimulated, not to the whole muscle. In subject 4, FNS caused avoidance of the expected hypotrophy in recent injuries.

Only two of the subjects ( 1 and 2 ) continued the stimulation programme frequently enough after discharge from the hospital to maintain their muscle strength. Such low compliance is in agreement with earlier reports (Peckham, 1987).

In conclusion the results of this study showed that FNS was an outstanding efficient training method to increase the muscle strength in patients with upper motor neuron lesions, and probably for that purpose should be used more often than it is today. However, new techniques are needed to make FNS improve function in daily life.

\section{Acknowledgements}

This study was supported by grants from Birgit and Rolf Sunnaas' Memory Foundation, and from 'ESSO NORGE A/S'.

\section{References}

Brown MD, CotTer MA, Hudlicka O, VRBova G 1976 The effects of different patterns of muscle activity on capillary density, mechanical properties and structure of slow and fast rabbit muscles. Pfluegers Archiv. European Fournal of Physiology 361:241-250.

Brindley GS, Polkey CE, RushtaN DN 1978-1979 Electrical splinting of the knee in paraplegia, Paraplegia 16: 428-435.

Cybulski, GR, PENN RD, JAEger RJ 1984 Lower extremity functional neuromuscular stimulation in cases of spinal cord injury. Neurosurgery 15:132-146.

GRIMBY G 1982 Isokinetic training. Fournal of Sports Medicine 3:61-64.

HeLlsING A-L 1986 Funktionell Elektrisk Stimulering (FES). Sjukgymnasten 1:13-15.

HJeltnes N, Pedersen U 1983 Isokinetic muscle strength measurements. Tidsskrift Nor Lageforen 26: $1822-1826$.

HJELTNES N 1986 Cardiorespiratory capacity in tetra- and paraplegia shortly after injury. Scandinavian Fournal of Rehabilitation Medicine 18:65-70.

HJELTNES N, VOKAC Z 1979 Circulatory strain in every day life of paraplegics. Scandinavian fournal of Rehabilitation Medicine 11:67-70. 
Isakov E, Mizrahi J, Graupe D, Becker E, Najenson T 1985 Energy cost and physiological reactions to effort during activation of paraplegics by functional electrical stimulation. Scandinavian Fournal of Rehabilitation Medicine Supplement 12:102-107.

LIBERSON WT, HolmQUeST HJ, ScOT D, Dow M 1961 Functional electrotherapy: Stimulation of the peroneal nerve syncronized with the swing phase of the gait in hemiplegic patients. Archives of Physical Medicine and Rehabilitation 42:101-105.

Peckham Hunter P 1981 Functional neuromuscular stimulation. Physical Technology 12:114-122.

PECKham HUNTER P 1987 Functional electrical stimulation: Current status and future prospects of applications to the neuromuscular system in spinal cord injury. Paraplegia 25:279-288.

RAY CD 1978 Electrical stimulation: New methods for therapy and rehabilitation. Scandinavian Fournal of Rehabilitation Medicine 10:65-74.

RILEy DA, Allin EF, BAJD T 1973 The effects of inactivity, programmed stimulation and denervation on the histochemistry of skeletal muscle fiber types. Experimental Neurology 40:391-413.

STEFANOVSKA A, VodovNIK L 1985 Change in muscle force following electrical stimulation. Scandinavian Fournal of Rehabilitation Medicine 17:141-146.

Thistle HG, Hislop HJ, Moffroid M, Lowman EW 1967 Isokinetic Contraction: A new concept of resistive exercise. Archives of Physical Medicine and Rehabilitation 48:279. 